\title{
A STUDY ON HEALTH PROBLEMS AMONG THE ELDERLY RESIDING IN
}

\section{SELECTED OLDAGE HOMES OF HYDERABAD CITY}

\author{
AYESHA SULTANA AHMED ${ }^{1} \&$ P. RADHA RANI ${ }^{2}$ \\ ${ }^{1}$ Research Scholar, College of Home Science, Professor Jayashankar Telangana State Agricultural \\ University, Hyderabad, Telangana, India
}

${ }^{2}$ Professor \& Head, Department of Resource Management and Consumer Sciences, College of Home Science, Professor Jayashankar Telangana State Agricultural University, Hyderabad, Telangana, India

\begin{abstract}
Health of an elderly during old age is an asset, as aging brings in gradual changes with passing of time and physiological changes, that occur with age prevent life beyond 70 s and 80 s, and more from being what it was in the younger years. There are innumerable things one can do, to improve the health and longevity and reduce the risk for physical and mental disability as one gets older. The functional capacity (such as muscular strength and cardiovascular output) of individuals increases in childhood, peaks in early adulthood and eventually declines as the individual grows older. Elderly men and women above the age of sixty years were included in the study and were divided equally. The frequency of medical check-up was determined by the health problems of the respondents', like BP, diabetes, heart problem, hearing and vision problem, cancer and skin allergies. Majority (67\%) of the respondents' were suffering from vision problem, followed by hearing problem (60\%), diabetes (58\%), knee pain (45\%), blood pressure (30\%), an equal percentage suffering from joint pains (13\%) and asthma (13\%).

KEYWORDS: Gradual Changes, Childhood \& Hearing and Vision Problem
\end{abstract}

Received: Nov 09, 2017; Accepted: Nov 29, 2017; Published: Jan 05, 2018; Paper Id.: IJMPSFEB20183

\section{INTRODUCTION}

Elderly or old age consists of ages nearing or surpassing the average life span of human beings. The National Policy on Older Persons defines "senior citizen" or "elderly" as a person, who is of age 60 years or above. Changes in the body structure and morphology occur over its lifetime. At every stage of life, there are physical and sensory changes in the human body. The functional capacity (such as muscular strength and cardiovascular output, figure 1) of individuals increases in childhood, peaks in early adulthood and eventually declines.

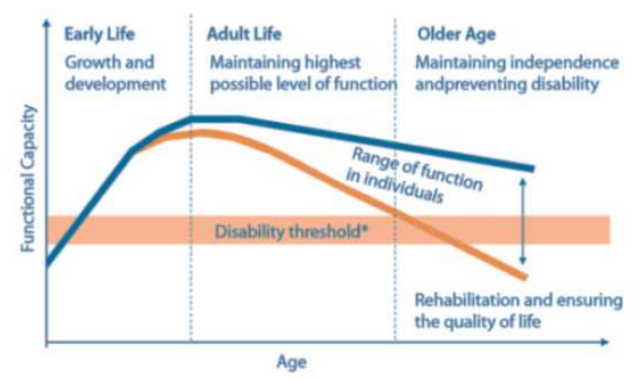

Figure 1: Maintaining Functional Capacity over the Life Course 
An old age home should provide a comfortable living space and a sense of belongingness to its inhabitants. It should provide security and medical aid at the time of emergencies to the senior citizens. With the advancement of age, several negative changes occur in the body and the physical capability of people decreases. Health of an elderly during old age is an asset; as aging brings in progressive changes with passing of time and physiological changes that occur with age prevent life beyond 70s, 80s, and more from being what it was in the younger years. There is a lot one can do to improve the health and longevity and reduce the risk for physical and mental disability as one gets older. The risk for certain medical conditions_-such as heart attack, trips and falls, morbidity, dementia, diabetes, lung disease, chronic pain, some types of cancer and other health concerns increase with age. To cope up with this, they need assistance, which could be provided either by some other person or through use of technology.

\section{REVIEW OF LITERATURE}

Krishnaswamy and Usha (2001) conducted a study to assess the fracture threshold by the use of T scores amongst the South Indian population using dual energy X-ray absorptiometry and to analyze whether the T score, could predict an impending hip fracture. A prospective study for estimating bone mineral density (BMD) was done for 116 elderly patients (53 Males and 63 Females). Among them, 38 had sustained fractures. Mean of bone mineral density (BMD) in fracture case was 0.72 and in non-fracture cases was 0.8 . The study suggested a bone mineral density (BMD) value of 0.72 as a fracture threshold in South Indian Elderly, a population to be targeted for fall prevention strategies.

Niinoet. al (2002) conducted a survey to understand the incidence and circumstances of falls among communitydwelling elderly people in Tokoname-shi, Aichi Prefecture. A total of 2,774 elderly people were interviewed. The incidence of falls among the respondents was $13.7 \%$. It was significantly higher among women (17.2\%) than men $(8.3 \%, \mathrm{P}<0.001)$. Incidence of falls increased as the individuals aged. Ten percent of the falls caused fracture among the respondents. The incidence of falls was extremely high during the daytime and in outdoor areas. Falls occurred most frequently while walking.

Li et al. (2002) in his study indicated that, in China, the incidence of falls occurring outdoors was much higher than occurring indoors, the most frequent locations for falls outdoors (68.2\% were streets), and frequent locations for falls indoors (31.8\%) were bedroom, bathroom and stairs.

Joshi et al. (2003) conducted a cross-sectional survey of 200 subjects over 60 years old (100 each from the urban population of Chandigarh City and the rural population of Haryana State of India), using a cluster sampling technique. The period of study was from July 1999 to April 2000. One hundred and three (51.5\%) subjects had fallen out of the total sample. Fracture was reported by $21.3 \%$ and other injuries by $79.6 \%$ of those who had fallen. Fractures among females $(26.4 \%)$ were more compared to males $(16 \%)$ and fracture was seen more in urban subjects $(29.4 \%)$ compared with rural subjects (13.4\%). The results of the analysis indicated that history of fall and fall frequency was significantly associated with disability and psychological distress. The significance of falls increased and the injury rate was highest among the oldest old (80 years).

Iwarsson et al. (2009) conducted a study on eight hundred and thirty-four older adults on the age group of 75-89 years. The location of the study was Urban districts in Sweden, Germany and Latvia. Survey method was adopted along with data collection from home visits, followed by self-reports about falls. The participants reporting falls were frailer than the non-fallers. The number of environmental barriers in the home was similar for the fallers and non-fallers; the 
magnitude of person-environment fit problems was higher among the fallers. The person-environment fit problem variable was a stronger fall predictor (odds ratio $(\mathrm{OR})=1.025 ; \mathrm{P}=0.037$ ) than number of environmental barriers. Fallers had also experienced lower usability of their home.

Banker (2011) et al. conducted a study to understand the health related problems of the elderly residing at geriatric homes of urban and peri urban areas of Ahmedabad. The period of study was form January 2008 to January 2009. Among the total sample of 530 inmates, $45.85 \%$ were males and $54.15 \%$ were females. Ninety four per cent of them reported one or more health problems. Thirty seven per cent of them were obese and $12 \%$ were underweight. Other health problems included: loss of teeth $(70 \%)$, joint pain $(60.2 \%)$, impaired vision $(44.2 \%)$, weakness $(34.9 \%)$, and insomnia (34\%). $82.3 \%$ were using spectacles followed by walking sticks $(21.7 \%)$ and denture $(12.8 \%)$. The main health related problems were osteoarthritis (54.9\%), hypertension (54.2\%), cataract (16\%) and diabetes mellitus (14.9\%).

Anitha et al. (2012) explored the health problems of elderly staying in old age homes of Chennai city. Data on health problems was collected by clinical examination and available medical records. Medical services were available in all the homes. Only $3.3 \%$ of elders did not have any health problem and the remaining elders were suffering from one or more health problems. Major health problems of elders were cardiovascular diseases $42.8 \%$, dental problem $37.6 \%$ and visual problem $35.1 \%$.

The purpose of the study carried out by Kashyap (2012) was to appraise occurrence of accidents among inmates of old age homes. Purposive sampling design was chosen to select the samples in two regions of Uttarakhand State i.e. Kumaon and Garhwal. The data was collected using personal interview technique. The elderly people were in the age range of 60-70 years. The mean age was 72.5 year; the female sex ratio was greater than male. The number of elderly (53.3 $\%)$ who had fallen was in the age group of 70-80 years; among them 75 per cent were females. The causes of accidents were slip followed by fall. "Skid Resistance Polycemtiles" developed by Central Building Research Institute, Roorkee (India), were recommended for old age homes.

Bhatt et al. (2014) examined the type of health problems among the inmates in two old age homes of Vadodara city. A total of 50 inmates were interviewed. The results indicated that majority of them were suffering from blood pressure (54\%); weaknesses (44\%) followed by pain/ tingling in lower limbs (38\%), sleep disturbances (36\%), breathlessness (32\%), back pain and gastric problem. Other health problems reported were thyroid, heart attack, arthritis, hysteria, paralysis and diabetes. It was observed that majority of inmates were suffering from health problems associated with ageing.

From the above review, it can be concluded that the health of the elderly can be improved with proper planning and grouping of rooms. There are various age related problems like diabetes, blood pressure, knee problems, joint paints that increases with age and can be controlled through proper medication, clinical test and exercises. The design of the oldage homes, availability of facilities and appropriate furniture also has a significant impact on the health of the elderly.

\section{METHODOLOGY}

\section{Research Design}

A case study research design was chosen rather than an extensive statistical survey. 


\section{Location of the Study Sample}

Twin cities of Hyderabad and Secundrabad

\section{Selection of Sample}

Sampling is the process of selecting a number of respondents for a study, in such a way that, they represent the larger group from which they were selected (Kerlinger, 1995). Multistage sampling procedure based on specific criteria was followed for selecting cases for the present study:

Selection of Old Age Homes: Old age homes, operationally existing were selected. Based on type of institutional organization and permissions obtained for conducting study as criteria, old age homes from five zones were selected purposively and thus, 10 were taken as total sample.

\section{Selection of Subjects}

From each old age home, based on dependency in managing the daily activities and willingness to cooperate as the criteria, about 12 respondents were purposively selected equally representing the two categories viz. elderly who manage by self, and elderly who manage with support. Thus, the total samples for the study were 120 elderly drawn from 10 old age homes.

\section{Tools used for the Study}

The data was collected from the respondents about their health profile and their frequency of medical checkup using the personal interview technique.

\section{Statistical Analysis}

The data collected was computed and interpreted using statistical techniques like, frequency and percentages.

\section{RESULTS AND DISCUSSIONS}

\section{General Profile of the Respondents}

Majority (36\%) of the respondents belonged to the age group of $70-80$ years, while $30 \%$ of the respondents belonged to $60-70$ years, $25 \%$ to the age group of 80-90 years and the remaining 9\% were above 90 years. Elderly men and women above the age of sixty years were included in the study and were divided equally. Majority (48\%) of the men were graduates, $5 \%$ were retired government employees, $7 \%$ were postgraduate, $3 \%$ were educated up to high school and the remaining $37 \%$ were illiterate. Among the women, only 10\% were graduates, $5 \%$ were retired government employees, $4 \%$ were post graduates and majority $(80 \%)$ of them were illiterate.

\section{Frequency of Medical Check-up}

This section represents the number of times the individual goes for his/her medical check-up. The results are given below:

$(\mathbf{N}=120)$ 
Table 1: Distribution of the Sample according to the Frequency of Medical Check-up

\begin{tabular}{|l|c|}
\hline $\begin{array}{c}\text { Frequency of Medical } \\
\text { Check-up }\end{array}$ & Frequency (\%) \\
\hline Once in a month & $51(43)$ \\
\hline As \& when required & $49(40)$ \\
\hline Once in a week & $5(4)$ \\
\hline Once in 6 months & $2(2)$ \\
\hline Twice in a month & $6(5)$ \\
\hline Once in 15 days & $7(6)$ \\
\hline
\end{tabular}

*Figures given in parenthesis indicate percentages

The results in the table 1 revealed that $43 \%$ of the respondents' go for medical check-up once in a month, followed by $40 \%$ who go whenever required, $6 \%$ go once in 15 days, $5 \%$ go twice in a month and 2 per cent once in six months. The frequency of medical check-up depends on the health problems of the respondents, like BP, diabetes, heart problem, hearing and vision problem, cancer and skin allergies.

\section{Health Problems of the Respondents}

The table 2 given below shows the health problem of the respondents residing in old age home.

Table 2: Distribution of the Sample according to the Health Problems

\begin{tabular}{|l|c|}
\hline \multicolumn{1}{|c|}{ Health Problems } & Frequency (\%) \\
\hline Diabetes & $70(58)$ \\
\hline Heart Problem & $48(40)$ \\
\hline Arthritis & $11(9)$ \\
\hline Asthma & $15(13)$ \\
\hline Osteoporosis & $6(5)$ \\
\hline Backache & $15(13)$ \\
\hline Knee Pain & $54(45)$ \\
\hline Hearing Problem & $72(60)$ \\
\hline Vision problem & $80(67)$ \\
\hline Blood Pressure & $36(30)$ \\
\hline Joint Pains & $15(13)$ \\
\hline Trembling hands & $9(3)$ \\
\hline Skin Allergies & $2(2)$ \\
\hline Spondylitis & $3(3)$ \\
\hline Gastric trouble & $2(2)$ \\
\hline Cancer & $3(3)$ \\
\hline Prostrate Problem & $1(1)$ \\
\hline Obesity & $2(2)$ \\
\hline Anaemia & $2(2)$ \\
\hline Weak memory & $7(6)$ \\
\hline Parkinson's Disease & $1(1)$ \\
\hline
\end{tabular}

*Figures given in parenthesis indicate percentages

The results reveal that majority $(67 \%)$ of the respondents' were suffering from vision problem, followed by hearing problem $(60 \%)$, diabetes $(58 \%)$, knee pain $(45 \%)$, blood pressure $(30 \%)$, an equal percentage suffering from joint pains (13\%) and asthma (13\%). The remaining were suffering from arthritis (9\%), trembling hands (3\%), spondylitis (3\%), cancer $(3 \%)$, obesity $(2 \%)$, anemia $(2 \%)$, prostrate $(1 \%)$ and Parkinson's disease $(1 \%)$. Similar health problems were found in a study conducted by Banker et al (2011), it revealed that $93.77 \%$ reported one or more health related complaints. $37.4 \%$ 
were obese and $11.9 \%$ were underweight. Most common presenting symptoms were: loss of teeth $(70 \%)$, joint pain (60.2\%), impaired vision (44.2\%), weakness (34.9\%), and insomnia (34\%). 82.3\% were using spectacles followed by walking sticks $(21.7 \%)$ and denture (12.8\%). The main health related problems were osteoarthritis $(54.9 \%)$, hypertension $(54.2 \%)$, cataract $(16 \%)$ and diabetes mellitus $(14.9 \%)$.

\section{CONCLUSIONS}

The growth of the elderly population in the coming years will bring unprecedented burdens of morbidity and mortality across the country. The key challenges to access to health for the Indian elderly include, social barriers shaped by gender and other axes of social inequality (religion, caste, socioeconomic status, and stigma). Physical barriers include reduced mobility, declining social engagement, and the limited reach of the health system. Health affordability constraints include limitations in income, employment, and assets, as well as the limitations of financial protection offered for health expenditures in the Indian health system.

\section{REFERENCES}

1. Krishnaswamy. B and Usha. G, (2002) "Bone Mineral Density and Fracture Threshold in South Indian Elderly", Journal of the Association of Physicians of India, Volume 50 February.

2. Banker K, Prajapati B, Kedia G (2011)., "Study of health profile of residents of geriatric home in Ahmadabad district" National Journal of Community Medicine Volume 2 Issue 3 Oct-Dec

3. LiL, WangS, YangZ, et al (2002), "A study on risk factors for falling down in elderly people of rural areas in Laizhou City", Chinese Journal of Geriatrics, 21(5):370-372.

4. G. N. Dwivedi et al., A Study of Childhood and Adolescent Obesity with Special Reference to Effect of a Combined Intervention Therapy, International Journal of Medicine and Pharmaceutical Sciences (IJMPS), Volume 6, Issue 3, May - June 2016, pp. 21-28

5. Joshi K, R and Avasthi A, (2003), "Morbidity profile and disability among elderly people in Northern India", International Journal of Epidemiology;32:978-987.

6. Iwarsson S, Horstmann V, Carlsson G, Oswald F, Wahl HW, (2009), "Person--environment fit predicts falls in older adults better than the consideration of environmental hazards only",Clinical Rehabilitation Journal June;23(6), Pp-558-67

7. Rani M A, Palani, Sathiyasekaran, (2012) "Morbidity profile of elders in old age homes in Chennai", National Journal of Community Medicine Volume 3, Issue 3, July - September.

8. Kashyap S. N(2012),Occurrence of accident among inmates of old age homes of Uttarakhand, India, Asian Journal of Home Science Volume 7, Issue 2, December, pages- 456-460

9. Bhatt BM, Vyas S, Joshi J P, (2014) “Ageing and Health: A health profile of inmates of old age home”, National Journal of Community Medicine, Volume 5, Issue 1, January-March. 